Published in "Bulletin of the Peabody Museum of Natural History

55(2): 201-214, 2014"

which should be cited to refer to this work.

\title{
Allaeochelys libyca, a New Carettochelyine Turtle from the Middle Miocene (Langhian) of Libya
}

\author{
Philipe E. Havlik, ${ }^{1,2}$ Walter G. Joyce ${ }^{3}$ and Madelaine Böhme ${ }^{1,2}$ \\ ${ }^{1}$ Corresponding author: Department of Geosciences, University of Tübingen, \\ Sigwartstrasse 10, 72076 Tübingen, Germany \\ _email: philipe.havlik@senckenberg.de \\ ${ }^{2}$ Senckenberg Center for Human Evolution and Palaeoenvironment, \\ Sigwartstrasse 10, 72076 Tübingen, Germany \\ ${ }^{3}$ Department of Geosciences, University of Fribourg, \\ Chemin du Musée 6, 1700 Fribourg, Switzerland
}

\begin{abstract}
Fossil carettochelyine turtles are well known from the Paleogene of Europe (Allaeochelys), North America and Asia (Anosteira); however, the previously known Neogene fossil record is highly fragmentary and was therefore unsuitable for taxonomic analysis. In this work, we present a new carettochelyine taxon, Allaeochelys libyca, from the Middle Miocene (Langhian) of Gebel Zelten (Libya) based on an incomplete skull and disarticulated postcranial elements. The new taxon is diagnosed relative to the extant Carettochelys insculpta based on the placement of the foramen posterius canalis carotici interni close to the fenestra postotica, the horizontal orientation of the tubercula basioccipitalis, the substantial contribution of the opisthotic to the base of the tubercula basioccipitalis, the presence of a triangular pterygoid fossa, the arrangement of the mandibular condyles along a plane and the presence of an extremely well-developed fossa at the base of the processus mandibularis. A phylogenetic analysis of pancarettochelyids confirms the monophyly of Carettochelyidae and Carettochelyinae but resulted in a paraphyletic taxon, Allaeochelys. For the sake of nomenclatural stability, we provisionally retain the genus Allaeochelys as paraphyletic relative to the extant Carettochelys insculpta.
\end{abstract}

KEYWORDS

Allaeochelys libyca, Pan-Carettochelys, Carettochelyidae, Trionychia, Gebel Zelten, Middle Miocene

\section{Introduction}

Pig-nosed turtles (Pan-Carettochelys) are a group of freshwater turtles that are closely related to softshell turtles (Trionychidae) (e.g., Hummel 1929; Meylan 1987). The only extant taxon, Carettochelys insculpta, is restricted to southern New Guinea and northern Australia (Ernst and Barbour 1989). The habitat of C. insculpta is strictly aquatic and restricted to tropical to subtropical climates (Ernst and Barbour 1989). In addition to fragments from Laos (Lapparent de Broin 2004) and Mongolia (Shuvalov and Tchikvadze 1979), the Cretaceous fossil record of the group only consists of the late Early Cretaceous Kizylkumemys khoratensis Tong et al. 2005 from Thailand and the early Late Cretaceous K. schultzi Nessov
1977 from Uzbekistan. The Paleogene fossil record, by contrast, is extremely rich and includes material from North America, Europe and Asia (e.g., Hay 1908; de Broin 1987; Hutchison et al. 2004; Tong et al. 2009; Tong et al. 2010). The Neogene record, once again, is composed of only a few fragmentary remains from disparate localities, in particular shell fragments from the Miocene of Germany (Joyce, Klein et al. 2004), Papua New Guinea (Glaessner 1942), the Democratic Republic of the Congo (Hirayama 1992) and Egypt (Dacqué 1912; Lapparent de Broin 2000), which provide little insight into morphological changes and phylogenetic relationships of the immediate stem lineage of $C$. insculpta. New material from Gebel Zelten (Jabal Zaltan), Libya, includes shell material of at least two individuals 
and only the second known cranial remains of a carettochelyine from the Neogene (Meylan 2009). The purpose of this contribution is to provide a comprehensive description of the new fossil material and to discuss its phylogenetic and biogeographic implications.

The following institutional abbreviations are used: BMNH, British Museum of Natural History, London, UK; BSPG, Bayerische Staatssammlung für Paläontologie und Geologie, München, Germany; CRI, Chelonian Research Institute, Oviedo, Florida, USA; NHMB, Natural History Museum Bristol, Bristol, UK; SNG, Senckenberg Forschungsinstitut und Naturmuseum, Frankfurt am Main, Germany; and, YPM VPPU, Division of Vertebrate Paleontology Princeton University Collection. Peabody Museum of Natural History, Yale University, New Haven, Connecticut, USA.

\section{Material and Methods}

The new carettochelyine material from Gebel Zelten is housed at the BSPG under the collection numbers BSPG 1991 II 96 and 97 (left hypoplastra), 110 (bridge peripheral), 113 (anterior peripheral), 114 (peripheral I), 130 (partial skull) and 131 (isolated, partial supraoccipital). A skull of Carettochelys insculpta (SNG 56626) and photographs of several other specimens (BMNH 1903.7.10.1; CRI 14, 3116, 4800) served as our comparative basis. Anatomical terminology herein follows that of Gaffney (1979) and phylogenetic nomenclature that of Joyce, Parham et al. (2004).

We included the new carettochelyine fossil and a broad sample of other fossil pancarettochelyids into the phylogenetic analysis of Joyce (2007) to rigorously analyze the phylogenetic relationships of pancarettochelyids in a global context. Newer versions of this matrix were not used (e.g., Joyce et al. 2011; Anquetin 2012; Sterli et al. 2013) because they universally added characters and taxa not relevant to trionychian systematics and because rampant homoplasy with the existing analysis already proved difficult to handle computationally. The newly added taxa are Kizylkumemys khoratensis Tong et al., 2005 (as described by Tong et al. 2005); K. schultzi Nessov, 1977 (as described by Nessov 1977); Anosteira pulchra (Clark, 1932) (as described by Clark 1932 and personal observation of YPM VPPU 16317,
16318 by W.G. Joyce); Anosteira ornata Leidy, 1871 (as described by Hay 1906 and personal observation of type material by W.G. Joyce); Anosteira manchuriana Zangerl, 1947 (as described by Zangerl 1947 and personal observation of type material by W.G. Joyce); Anosteira maomingensis Chow and Liu, 1955 (as described by Chow and Liu 1955); Anosteira mongoliensis Gilmore, 1931 (as described by Gilmore 1931 and personal observation of type material by W.G. Joyce); Allaeochelys lingnanica (Young and Chow, 1962) (as described by Young and Chow 1962); Allaeochelys crassesculpta (Harrassowitz, 1922) (personal observation of material by W.G. Joyce); Allaeochelys delheidi (Dollo, 1886) (as described by Dollo 1886 and personal observation of type material by W.G. Joyce); Allaeochelys magnifica (Hutchison et al., 2004) (as described by Hutchison et al. 2004); Allaeochelys parayrei Noulet, 1867 (as described by de Broin 1977); and the new taxon described herein. Genus assignments follow Joyce (2014). Characters 60 and 89 of Joyce (2007) were modified by adding a character state. Six new characters were added, mostly from the work of Meylan (1988), to help further resolve the phylogenetic relationships of the ingroup. All nonpancarettochelyid taxa were scored for the new character using the same sources as Joyce (2007). Both the complete list of characters (Appendix 1) and the final character taxon matrix (see Appendix 2, supplementary material available online) are provided.

Characters 7, 27, 33, 35, 54, 60, 61, 65, 68, 71, $85,98,120,133$ and 134 of Joyce (2007) form morphoclines and were ordered in all analyses. The new characters 137, 138, 141 and 142 and the modified version of character 89 also form morphoclines and were therefore also ordered in all analyses. All remaining characters were left unordered, and all characters were given equal weight. All analyses were performed using PAUP v. 4.0 b10 (Swofford 2002), and the shortest solutions were sought using 1,000 branch-and-bound searcher replicates with minimum branch lengths set to collapse.

We performed two separate analyses that only differ in the selection of ingroup and outgroup taxa. In the first analysis, the matrix was run fully intact (i.e., with all taxa and characters), but the analysis was aborted after more than 10,000 equally parsimonious solutions with 409 steps 


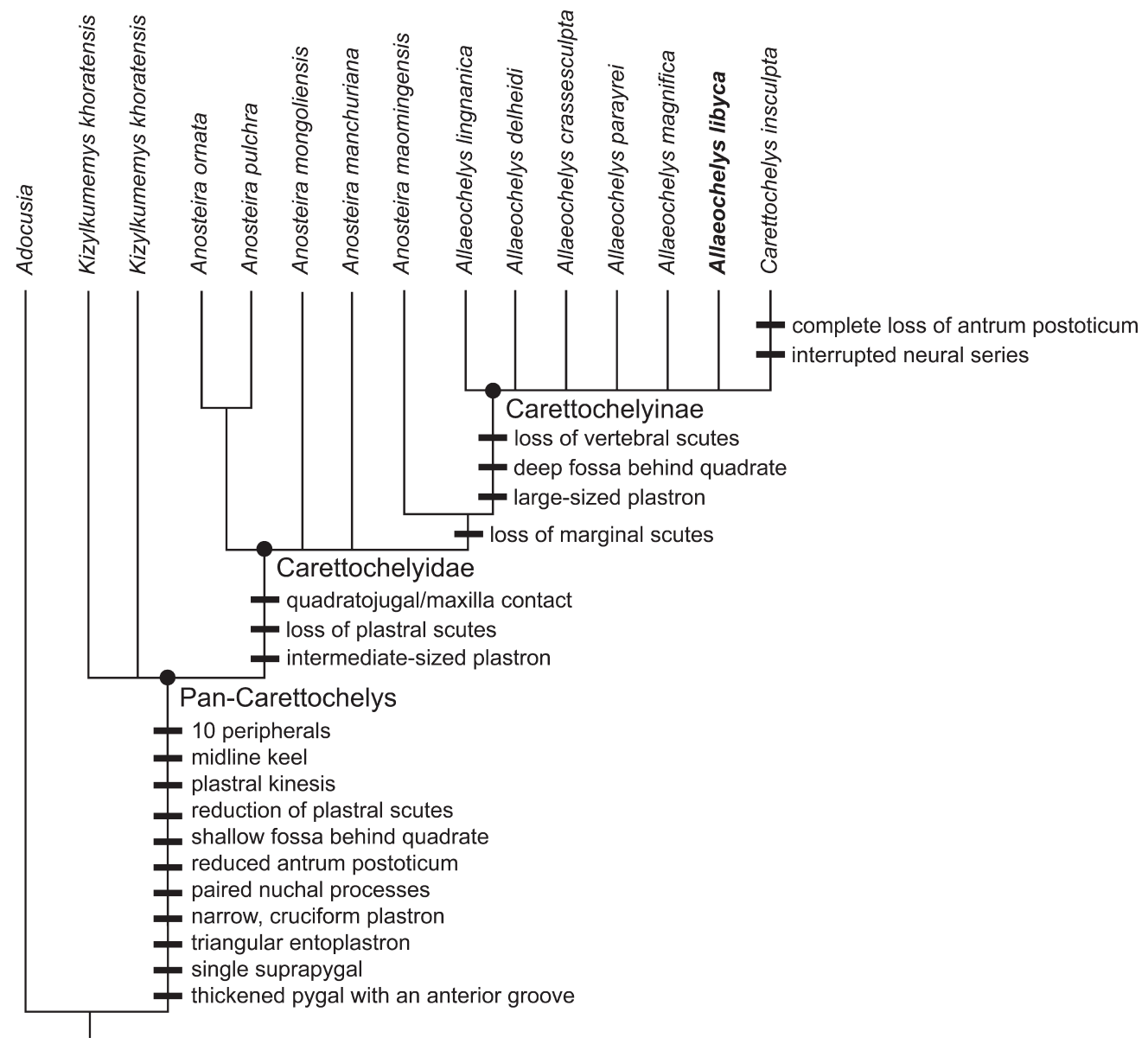

FIGURE 1. The Adams consensus topology summarizing the 32 most parsimonious solutions that resulted from the phylogenetic analysis presented herein. The diagnostic characters that diagnose all primary pancarettochelyid clades are provided below these nodes.

were found in the first iteration. The strict consensus tree of these 10,000 retrieved a monophyletic Pan-Carettochelys, Trionychia and Pan-Trionychia, thereby revealing that the great number of trees is the result of rogue taxa and that the relationships of Pan-Trionychians are unproblematic, even in this global context.

For the second analysis, we significantly modified the sample by restricting the ingroup to PanCarettochelys and by using Adocusia as the outgroup, thereby enabling us to retrieve all most parsimonious solutions. The second analysis retrieved, after filtering, 32 most parsimonious solutions with 43 steps. The Adams consensus tree and the distribution of apomorphies are provided (Figure 1).

\section{Geological Settings}

Gebel Zelten is an elongate, approximately $60 \mathrm{~m}$ high, sedimentary ridge situated about $200 \mathrm{~km}$ south of the Gulf of Sidra in what is currently $\mathrm{Al}$ Wahat District (former Governorate of Cyrenaica), Libya (Figure 2). The fossil-bearing sections are exposed along the southern slopes of the ridge at various sites (Figure 2). The material described herein was found at the localities "MS 2" (i.e., measured section 2) and "Wadi Shatirat" (for details, see Wessels et al. 2003). These sites correspond to the sites " $\mathrm{H}$ - Area 6409" and "LP - Areas 6412-16” of Savage and Hamilton (1973), respectively. All specimens were accidentally intermixed, and it is therefore not possible 


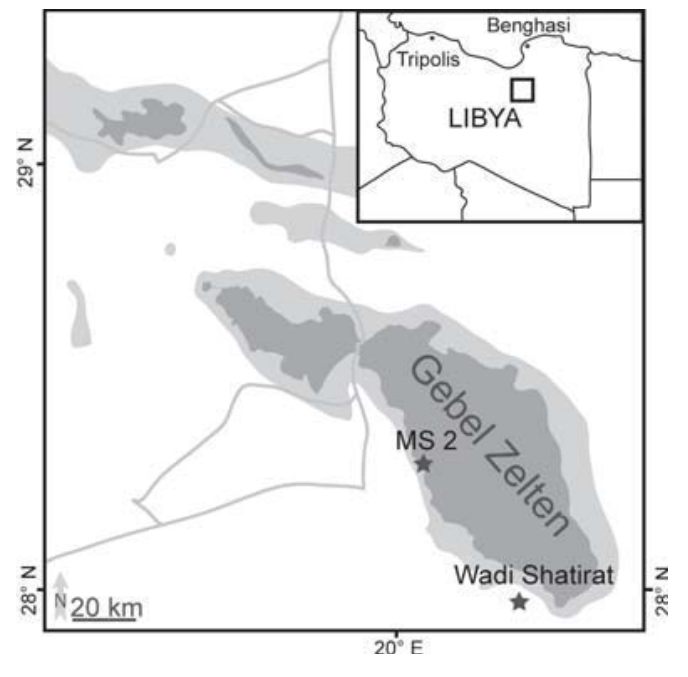

FIGURE 2. Geographic position of the localities "MS 2" and "Wadi Shatirat" in the Gebel Zelten area, Libya.

anymore to reconstruct which specimen originated from which precise locality.

Even though fossils were already discovered at Gebel Zelten by Ardito Desio in 1931, comprehensive scientific work did not start until Savage and Hamilton (1973) described the large mammal remains and provided a preliminary faunal list. Their work was based on excavations that took place between 1957 and 1968. Oldrich Fejfar collected additional fossils from 1982 to 1997 at Gebel Zelten, whereas Ali el Arnauti and Remmert Daams undertook expeditions in 1997 searching for large and small mammals (Wessels et al. 2003). The small mammal assemblage was described by Hamilton (1973), Wessels et al. (2003) and Fejfar and Horáček (2006). Publications on large mammals include Savage (1971), Savage and Hamilton (1973), Harris (1973), Delson (1979) and Pickford (2006). A preliminary description of the crocodilian remains housed at NHMB was given by Ginsburg and Buffetaut (1978) and Llinás Agrasar (2004), the latter using open nomenclature only. Chelonian remains have not been described in detail so far but were mentioned in Lapparent de Broin (2000). The material described herein was acquired as part of a collection by the BSPG from Fejfar in 1991. The collection also includes turtle shell remains attributable to Mauremys sp., a giant testudinid, and a large pelomedusoid, whereas disarticulated crocodile remains are attributable to Rimasuchus and Euthecodon (Havlik 2007).
The fossil-bearing horizons of Gebel Zelten lithostratigraphically belong to the Maradah Formation (Desio 1935). According to descriptions given by Savage and Hamilton (1973) and Fejfar and Horáček (2006), sedimentary patterns of the different sections from Gebel Zelten can be interpreted as fluviatile in origin. Thicker beds are interpreted as clastic channel fillings consisting of sand, gravel and reworked clay pebbles. The upper layers are described as cross-bedded sandstones intercalated by bioturbated layers. This corresponds to the distal facies of a northwardflowing river system, with its origins in the Tibesti Massif, called the Paleo-Sahabi. This anastomosing river system seems to have been almost identical to the Eo-Sahabi known from Upper Miocene of the same region (Griffin 2010). This interpretation is confirmed by data of the mollusk fauna from Maradah Formation (Selley 1966), which confirm a transition from brackish to normal saline conditions north of Gebel Zelten at the time of the early Middle Miocene (Langhian).

The Miocene sediments of Gebel Zelten were first assigned by Savage and Hamilton (1973) to the early Miocene (Burdigalian) based on small and large mammal biochronology. Subsequent fieldwork by Fejfar in the years 1982 and 1983 resulted in additional fossil material and the more detailed stratigraphic subdivision by Wessels et al. (2003), which distinguishes three levels: two of Burdigalian age (18-19 and 16-17 Ma) and one of Langhian age (14-16 Ma). This dating scheme is corroborated by ostracod and mollusk biochronology of interfingering marine sediments in eastern Libya (Tawadros 2012). The exact sites from which the carettochelyine specimen described herein were collected could not be identified, but according to Wessels et al. (2003), both localities in question ("Wadi Shatirat" and "MS 2"; Figure 2) are of Langhian age.

\section{Systematic Paleontology}

Testudines Batsch, 1788

Cryptodira Cope, 1868

Carettochelyidae Boulenger, 1887

Allaeochelys Noulet, 1867

Allaeochelys libyca sp. nov. Figures 3, 4 and 5

Holotype. BSPG 1991 II 130, incomplete skull. 
A
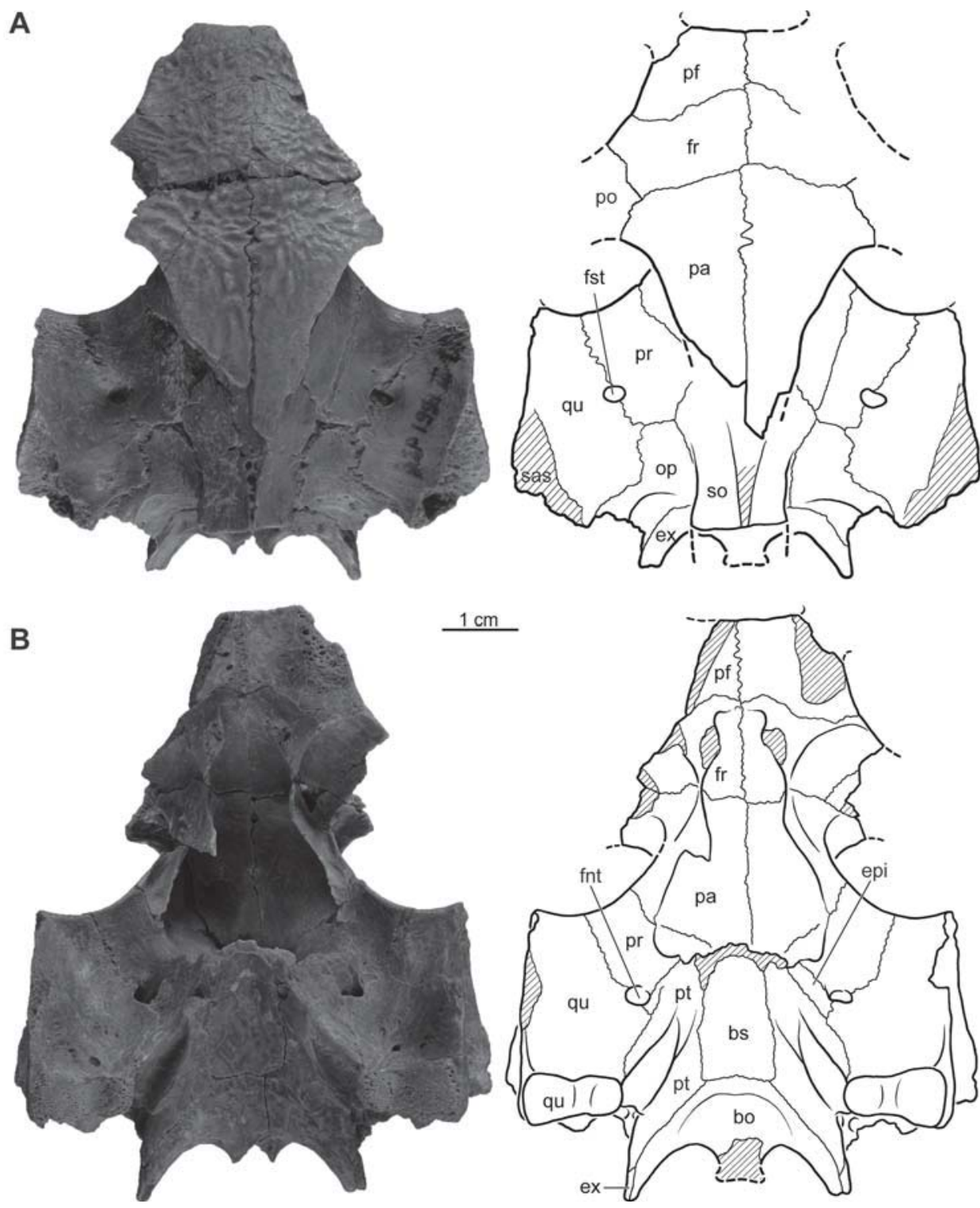

FIGURE 3. Holotype (BSPG 1991 II 130) of Allaeochelys libyca sp. nov., from the Middle Miocene (Langhian) of Gebel Zelten, Libya. A, Photograph and interpretative drawings in dorsal view. B, Photograph and interpretative drawings in ventral view. Abbreviations: bo, basioccipital; bs, basisphenoid; epi, epipterygoid; ex, exoccipital; fnt, foramen nervi trigemini; fr, frontal; fst, foramen stapedio-temporale; op, opisthotic; pa, parietal; pf, prefrontal; po, postorbital; pr, prootic; pt, pterygoid; qu, quadrate; sas, squamosal articulation site; so, supraoccipital.

Referred specimens. BSPG 1991 II 96 (left hypoplastron), 97 (left hypoplastron), 110 (bridge peripheral), 113 (anterior peripheral), 114 (peripheral I) and 131 (isolated, partial supraoccipital).

Type locality. Gebel Zelten (Jabal Zaltan), southwestern slopes, localities "MS 2" or "Wadi Shatirat," Al Wahat District, Libya (Wessels et al. 2003).
Type horizon. Lower Maradah Formation, Middle Miocene, Langhian (Desio 1935; Wessels et al. 2003).

Etymology. The specific name libyca is in accordance with the country of origin of the holotype.

Diagnosis. Allaeochelys libyca can be diagnosed as a representative of Carettochelyinae based on the presence of a deep fossa at 


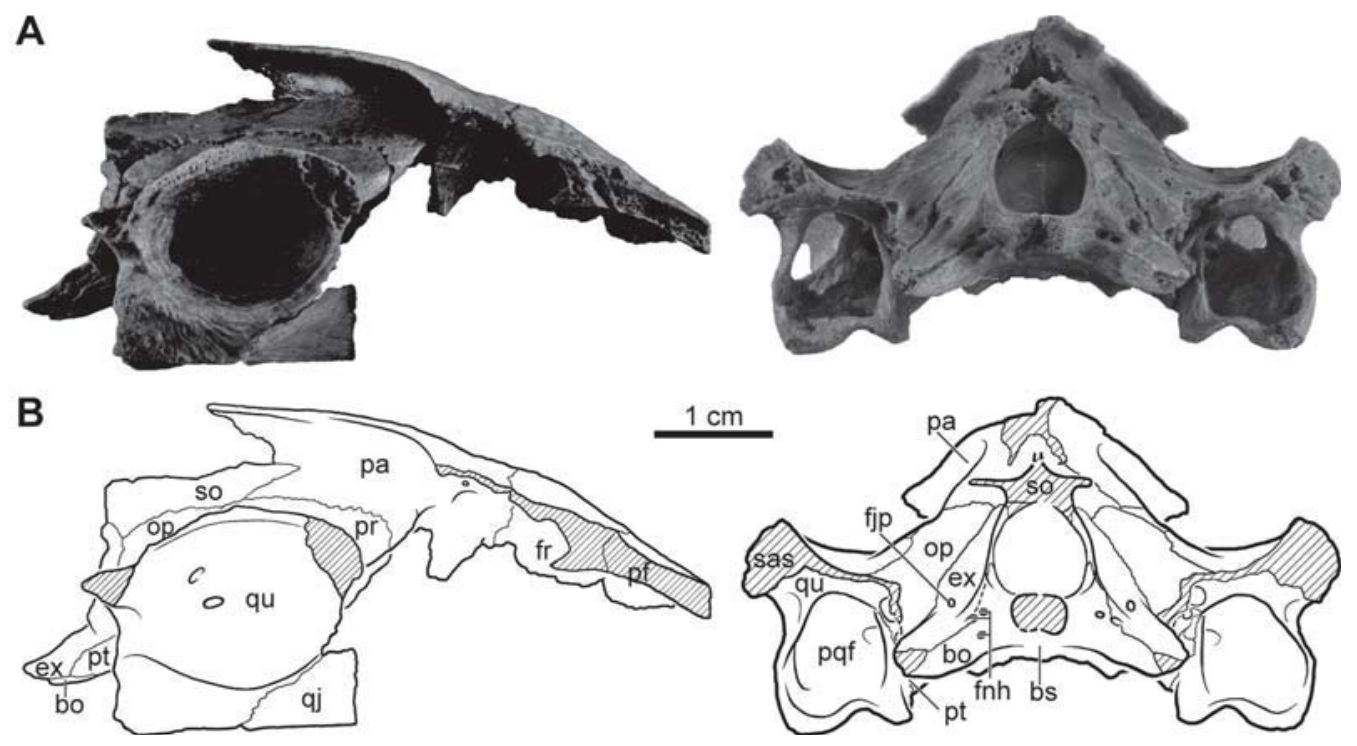

FIGURE 4. Holotype (BSPG 1991 II 130) of Allaeochelys libyca sp. nov., from the Middle Miocene (Langhian) of Gebel Zelten, Libya. A, Photograph and interpretative drawings in right lateral view. B, Photograph and interpretative drawings in posterior view. Abbreviations: bo, basioccipital; bs, basisphenoid; ex, exoccipital; fjp, foramen jugulare posterius; fnh, foramen nervi hypoglossi; fr, frontal; op, opisthotic; pa, parietal; pf, prefrontal; pqf, posterior quadrate fossa; pr, prootic; pt, pterygoid; qj, quadratojugal; qu, quadrate; sas, squamosal articulation site; so, supraoccipital.

the base of the processus mandibularis, a reduced antrum postoticum, absence of carapacial and plastral scutes and the presence of a broad plastron. Within Carettochelyinae, A. libyca can be diagnosed based on the placement of the foramen posterius canalis carotici interni close at the back of the skull close to the fenestra postotica, the horizontal orientation of the tubercula basioccipitalis, the large contribution of the opisthotic to the tubercula basioccipitalis, the primitive presence of a triangular pterygoid fossa, the arrangement of the mandibular condyles along a plane and the presence of a greatly inflated fossa at the base of the processus mandibularis.

\section{Description.}

Cranium. The skull (BSPG 1991 II 130; Figures 3 and 4) is preserved with major parts of the dorsal surface intact, but most of the quadratojugals, postorbitals, jugals and the supraoccipital crest are missing. The preserved median length is $51 \mathrm{~mm}$. In lateral view, both quadrates are almost completely preserved; whereas only a small, posterior fragment of the right quadratojugal remains, and the postorbitals and squamosals are missing completely. In occipital view, the skull is almost complete, except for the condylus occipitalis and the details of various bony ridges. The entire palate is missing in ventral view, but the basicranium is completely preserved. An isolated, distal fragment of a supraoccipital is furthermore preserved (BSPG 1991 II 131), which corresponds in size and preservation with BSPG 1991 II 130. The specimens preserve their uncrushed, original shape.

Dermal ornamentation. The prefrontals, frontals and parietals show a distinct dermal ornamentation, which is formed by ridges up to $8 \mathrm{~mm}$ long, $1.2 \mathrm{~mm}$ wide and up to $0.4 \mathrm{~mm}$ high that are separated by equally sized grooves. The ornamentation is radially developed from the center of every skull element.

Prefrontals. The posterior suture of the prefrontal with the frontal is slightly oblique, but mostly transverse. This suture is also slightly asymmetrical, as the right prefrontal is $2 \mathrm{~mm}$ shorter medially than the left prefrontal. Only the proximal portion of the descending process is preserved on the left side of the skull, and all potential ventral contacts are therefore obscured. The prefrontals form the dorsal roof of the confluent external nares. The dorsal rim of the external nares is oriented transverse, but a minute median spur is apparent that points toward the anterior. The prefrontals form more than half of the dorsal margin $(8 \mathrm{~mm})$ of the fossa orbitalis.

Frontals. The frontals form mediolaterally elongated rectangles. Anteriorly, the frontals articulate with the prefrontals and posteriorly with the parietals. The suture with the parietals is straight in dorsal view. The frontals form a shorter part $(5 \mathrm{~mm})$ of the dorsal rim of the fossa orbitalis relative to the prefrontals. The lateral suture with the postorbitals is only preserved on the left side, and only a small fragment of the postorbital is preserved. In ventral view, a pair of sagittal ridges is apparent that frame the broad, rounded sulcus olfactorius and that are confluent with the descending processes of the parietals.

Parietals. In dorsal view, the parietals form the posterior part of the skull roof and medially frame the deep upper temporal emargination. The parietals anterolaterally articulate with the postorbitals, anteriorly with the frontals and medially with one 

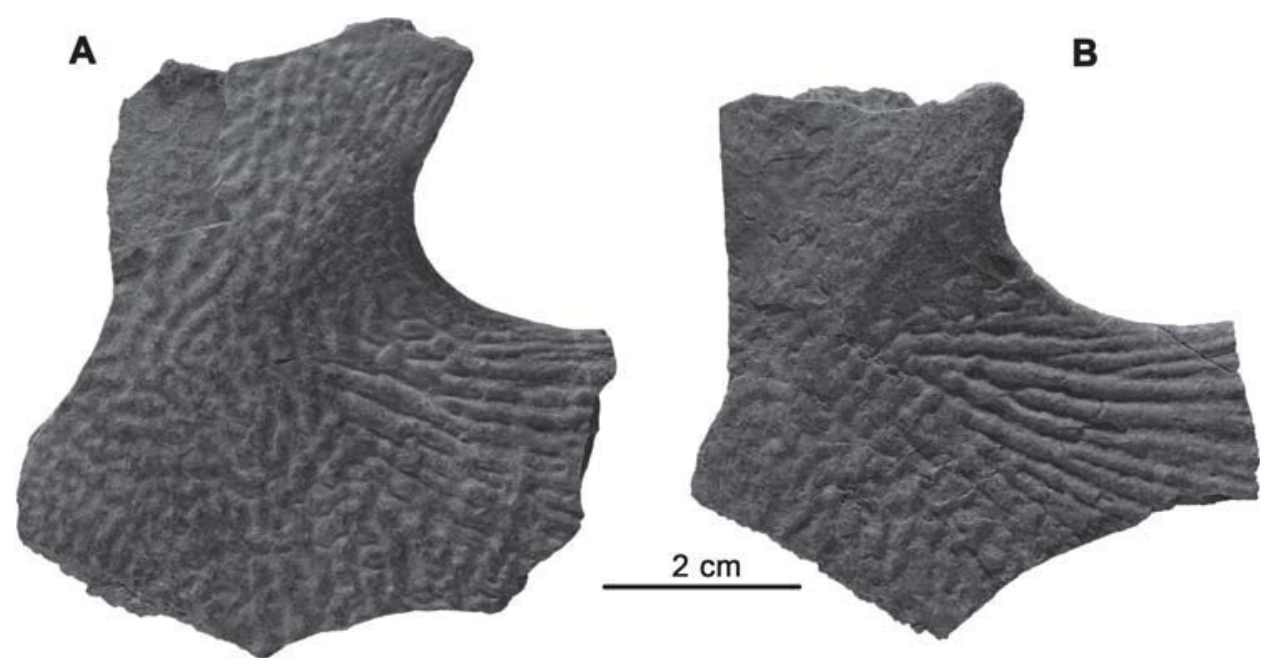

FIGURE 5. Allaeochelys libyca sp. nov., from the Middle Miocene (Langhian) of Gebel Zelten, Libya. Photographs of hypoplastra in ventral view. A, Left hypoplastron (BSPG 1991 II 96). B, Left hypoplastron (BSPG 1991 II 97).

another. Two prominent sinuosities are developed along the anterior half of the median suture. The posterior portion of the descending process of the parietals is $1 \mathrm{~mm}$ thick and articulates with the prootic laterally, with the supraoccipital posterolaterally but does not contact the opisthotic. The anterior portion of the descending process is much thinner than the posterior half; however, damage is extensive on both sides, and the ventral contacts are therefore obscured.

Supraoccipital. The supraoccipital of BSPG 1991 II 130 is preserved only in part. Within the upper temporal fossa (better preserved on the right side), the supraoccipital articulates anterolaterally with the parietals, laterally with the prootics and posterolaterally with the opisthotics. The crista supraoccipitalis is not preserved. The supraoccipital forms the complete dorsal border of the foramen magnum. Although fragmentary, the isolated supraoccipital (BSPG 1991 II 131) reveals that the supraoccipital crest forms broad, horizontal shelves that give the base of the crest a T-shaped cross section typical of trionychian turtles.

Prootic. Both prootics are preserved completely. In dorsal view, the prootics articulate anteromedially with the parietals, laterally with the quadrates, posteriorly with the opisthotic and medially with the supraoccipital and contribute to the foramen stapediotemporale. The sutures of the opisthotic, supraoccipital and prootic meet at a triple junction that roofs the cavum labyrinthicum. In an oblique anteroventral view, the prootics contact the quadrates laterally, the parietal medially and the epipterygoids and pterygoids ventrally and contribute to the dorsal margins of the anterior and posterior trigeminal foramina.

Opisthotic. In dorsal view, the opisthotic articulates with the prootic anteriorly, with the supraoccipital medially and with the quadrate laterally. The opisthotic forms the anterolateral part of the heavily elongated tuberculum basioccipitalis and thereby contacts the exoccipital and pterygoid, but not the basioccipital. The opisthotic forms the dorsal rim of the fenestra postotica but does not contribute directly to the foramen jugulare posterius.

Quadrate. Both quadrates are preserved with only minor damage. In lateral view, the quadrate primarily forms the anteroposteriorly elongate cavum tympani. The posterior wall of the cavum tympani is particularly thin and is therefore damaged on both sides of the specimen. The antrum postoticum is reduced to the size of a pinhead. The incisura columella auris is fully enclosed posteriorly and does not include the Eustachian tube. The quadrate contacts the quadratojugal anterior to the cavum tympani, and articular scars reveal that the quadrate contacted the squamosal posteriorly to the cavum tympani as well. The quadrate contributes to the upper temporal margin, and the squamosal therefore does not contact the postorbital or the quadratojugal above the cavum tympani.

In ventral view, the quadrate contacts the quadratojugal laterally, the prootic anteriorly and the epipterygoid and pterygoid medially and forms the lateral wall of the posterior trigeminal foramen. The condylus mandibularis is biconvex, and the lateral articulation surface is larger than the medial one. Both facets are arranged on a plane.

In posterior view, the quadrate contacts the opisthotic dorsolaterally, contributes to the margin of the fenestra postotica laterally, contacts the pterygoid anterolaterally and is deeply excavated by a large fossa that is situated above the condylus mandibularis. The bony walls that define this fossa are extremely thin.

Quadratojugal. Only a fragment of the right quadratojugal is preserved. It contacts the quadrate posteriorly and forms the horizontal ventral margin of the skull.

Exoccipital. The exoccipitals form the lateral and ventral border of the foramen magnum and contact the supraoccipital dorsally. The exoccipital broadly contacts the basioccipital and pterygoid ventrally and thereby contributes to the elongate tuberculum basioccipitalis and the occipital condyle. Each 
exoccipital is pierced by two foramina nervi hypoglossi and the foramen jugulare posterior. The foramen jugulare posterior is broadly separated from the fenestra postotica by a broad bony bar, which is formed by the exoccipital, opisthotic and pterygoid.

Basioccipital. The anterior part of the basioccipital is preserved but its contribution to the occipital condyle is missing due to damage. The basioccipital forms the ventral portion of the tubercula basioccipitalis, which points posterolaterally along the same horizontal plane as the rest of the skull. A shallow depression is restricted to the ventral side of the basioccipital. The basioccipital contacts the basisphenoid anteriorly, the pterygoids anterolaterally and the exoccipital posterolaterally.

Basisphenoid. The basisphenoid forms an anteroposteriorly elongated rectangle. It articulates laterally with the pterygoids and posteriorly with the basioccipital along a straight suture. The anterior suture with the palatines is preserved and broadly convex. The sella turcica is broad and forms an overhang that covers the enlarged and widely spaced foramina anterior canalis carotici cerebralis (sensu Rabi et al. 2013). The clinoid processes and the rostrum are damaged, and therefore, their morphology cannot be assessed.

Pterygoid. Only the posterior portions of both pterygoids are preserved from the anterior rim of the basisphenoid to the posterior border of the skull. The pterygoids form the entire margin of the foramen posterius canalis carotici interni, which is situated at the posterior end of the pterygoideus ridge just ventromedially to the fenestra postotica. There is no apparent ptery goid/pterygoid suture, however, along the posterior portion of the internal carotid canal. The pterygoids contribute to the ven trolateral portions of the tubercula basioccipitalis but do not reach the distal apex. The pterygoid fossa has a triangular shape and is not connected to the lower temporal fossa.

Epipterygoid. The epipterygoid cannot be discerned on the right side of the skull, but the posterior half is preserved on the left side. The epipterygoid is an anteroposteriorly elongate element that contacts the pterygoid ventrally, the quadrate posteriorly and the prootic dorsally. It furthermore forms the ventral margin of the posterior half of the trigeminal foramen. Possible anterior contacts with the parietal and palatine are not preserved due to damage.

Hypoplastron. Two similarly sized right hypoplastra (BSPG 1991 II 96 and 97) are available that roughly preserve the same portion of the inguinal buttress (Figure 5). In both cases, only a portion of the anterior suture with the hyoplastron is preserved, but the sutures with the right hypoplastron and xiphiplastron are missing. The ventral surface shows strong, radially developed dermal ornamentations, which are more distinct along the bridge and worn along the main body of the element. The great distance from the anterior rim of the element to the inguinal notch is consistent with an elongate bridge.

Peripherals. Three peripherals are preserved that document at least part of the carapace. BSPG 1991 II 114 can easily be identified as left peripheral I by its short medial suture with the nuchal and its rounded shape. BSPG 1991 II 113 can also be identified as an anterior peripheral by its elongate shape and lack of a bridge excavation, but its exact placement along the series is uncertain. BSPG 1991 II 110 can finally be identified as a bridge peripheral because it forms a $\mathrm{V}$ in cross section, but its placement within the series is obscured by damage. The external surface of all peripheral elements is decorated by distinct pustules, which contrast the low ridges found on the plastron.

\section{Discussion}

\section{Alpha Taxonomy}

Even though the fossil record of Pan-Carettochelys spans the Cretaceous and the Neogene, most of the taxa are based on shell remains, and little is known about the cranial anatomy of the group (Joyce 2014). To date, cranial material has only been reported for the Late Cretaceous Kizylkumemys schultzi (Nessov 1977) and the Eocene taxa Anosteira pulchra (Gaffney 1979), Allaeochelys crassesculpta (Harrassowitz 1922) and Allaeochelys delheidi (Lydekker 1889), but all descriptions are insufficient to allow making meaningful comparisons. We therefore restrict ourselves to making comparisons with the extant, but morphologically similar, Carettochelys insculpta.

The skull of Allaeochelys libyca greatly resembles that of Carettochelys insculpta (see Figure 6 for comparison) in the sculpturing of the dorsal surface, the distribution of sutures and overall shape. Several differences are nevertheless consistently apparent between $A$. libyca and all specimens of $C$. insculpta available to us that allow diagnosing A. libyca as a new taxon and that might be of interest in future phylogenetic analyses: (1) The foramen posterius canalis carotici interni of A. libyca is situated at the posterior end of the pterygoideus ridge close to the fenestra postotica. This foramen is situated medial to the pterygoideus ridge and distant from the fenestra postotica in C. insculpta. (2) The tubercula basioccipitalis of A. libyca are oriented in the same horizontal plane as the rest of the basicranium and point posterolaterally. The tubercula of $C$. insculpta, by contrast, are not aligned along a horizontal plane but rather curve strongly posteroventrally. (3) The opisthotic substantially contributes to the base of the tubercula basioccipitalis in A. libyca but barely reaches the base of this structure in C. insculpta. (4) The pterygoid fossa of A. libyca is triangular and not connected to the lower temporal fossa, whereas the pterygoid fossa 

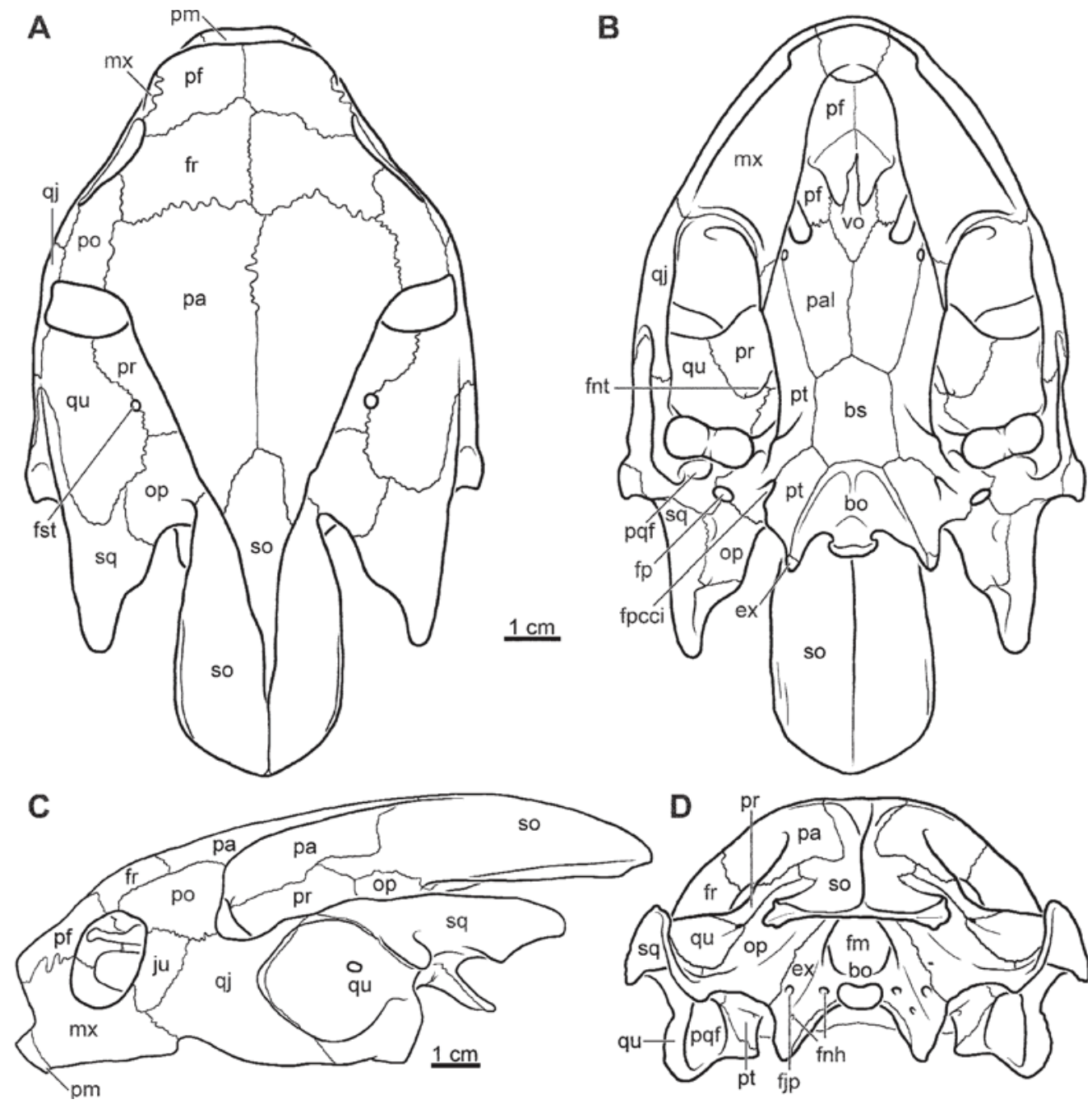

FIGURE 6. Interpretative drawing of the skull of Carettochelys insculpta based on SNG 56626. A, Dorsal view. B, Ventral view. C, Lateral view. D, Occipital view. Abbreviations: bo, basioccipital; bs, basisphenoid; ex, exoccipital; fjp, foramen jugulare posterius; fm, foramen magnum; fnh, foramen nervi hypoglossi; fnt, foramen nervi trigemini; fp, foramen postoticum; fpcci, foramen posterius canalis carotici interni; fr, frontal; fst, foramen stapedio-temporale; ju, jugal; mx, maxilla; op, opisthotic; pa, parietal; pal, palatine; pf, prefrontal; pm, premaxilla; po, postorbital; pqf, posterior quadrate fossa; pr, prootic; pt, pterygoid; qj, quadratojugal; qu, quadrate; so, supraoccipital; sq, squamosal; vo, vomer.

of C. insculpta is elongate and fully confluent with the lower temporal fossa. (5) The mandibular condyles are arranged along a plane in A. libyca instead of being inclined medially, as in $C$. insculpta. (6) The fossa at the posterior side of the processus mandibularis is almost as large as the quadrate, laterally defined by thin bony walls in A. libyca, and almost confluent with the fenestra postotica. The fossa is significantly smaller in $C$. insculpta, defined by thick bony walls and clearly separated from the fenestra postotica.
The previously listed characters amply distinguish the new taxon from Carettochelys insculpta. Future work on the cranial anatomy of Eocene carettochelyids will reveal whether the Libyan material can also be diagnosed relative to older taxa. Given the large temporal hiatus, however, that exists between Allaeochelys libyca and all previously named material from the Cretaceous and Paleogene, we feel confident that morphological differences will likely emerge that further support the validity of the new Neogene taxon. 
Phylogenetic Relationships of

Pan-Carettochelys

The first phylogenetic hypothesis of pancarettochelyid turtles was presented by Nessov (1976), who recognized two primary groups of pancarettochelyids using traditional taxonomic arguments. According to Nessov (1976), Anosteirinae consists of the Cretaceous taxon Kizylkumemys and the Paleogene taxon Anosteira, whereas Carettochelyinae consists of the Paleogene and Neogene taxon Allaeochelys and the extant Carettochelys insculpta. Meylan (1988) soon after confirmed this phylogenetic arrangement using a cladistic analysis that incorporated a broad sample of outgroups. This phylogenetic hypotheses, however, is at odds with the fossil record as it implies that carettochelyine turtles have a ghost lineage that extends from the Eocene to the Early Cretaceous.

We performed two phylogenetic analyses that primarily differ in the selection of ingroup and outgroup taxa. The first analysis was aborted prematurely after more than 10,000 equally parsimonious trees had been found. The strict consensus tree of these 10,000 equally parsimonious solutions, however, retrieves a monophyletic PanCarettochelys, Trionychia and Pan-Trionychia (i.e., Adocusia and Trionychia) and thereby reveals that the great number of trees found in the first analysis is not the result of homoplasy, but rather of many rogue taxa with shifting positions. A monophyletic Pan-Trionychia is consistent with most of the recent phylogenetic analyses (e.g., Meylan and Gaffney 1989; Joyce 2007; Danilov and Parham 2008; Tong et al. 2009; Joyce et al. 2011; Anquetin 2012; Sterli et al. 2013).

Given that Pan-Trionychia and Trionychia were universally retrieved in the first analysis, given that the monophyly of Pan-Carettochelys is unproblematic (Meylan 1987, 1988; Meylan and Gaffney 1989) and given that pancarettochelyid relationships are the primary focus of this analysis, we significantly simplified the second analysis by restricting the ingroup to Pan-Carettochelys and by using Adocusia as the outgroup. The Adams consensus tree and a list of diagnostic characters are provided (Figure 1).

Our phylogenetic hypothesis agrees with previous hypotheses in recognizing a monophyletic Carettochelyinae (i.e., the clade consisting of Allaeochelys spp. and Carettochelys insculpta).
However, our analysis was not able to retrieve any characters that would support the monophyly of Allaeochelys relative to C. insculpta. We see three nomenclatural solutions: (1) synonymize Carettochelys Ramsay 1887 with Allaeochelys Noulet 1867; (2) retain Allaeochelys as a paraphyletic taxon; or (3) assign all Allaeochelys taxa to monotypic genera. The first solution is highly problematic, as we see little value in disrupting nearly 150 years of nomenclatural stability by assigning the extant C. insculpta to the fossil-based genus Allaeochelys and because we are certain that neontologists will not accept this solution. The third solution we feel to be similarly problematic, as we see little value in the creation of many new genus names. We therefore decide to maintain the paraphyletic taxon Allaeochelys and to arbitrarily restrict Carettochelys to the extant taxon only. Using a similar set of arguments, we here note the likely paraphyly of taxa referred to Anosteira and Kizylkumemys but nevertheless suggest maintaining this name as a paraphyletic taxon and awaiting more detailed phylogenetic analyses (also see Joyce 2014).

Our phylogenetic analysis contradicts previous analyses by placing Anosteira as sister to Carettochelyinae to form the clade Carettochelyidae (sensu Joyce, Parham et al. 2004), which is primarily supported by the complete loss of plastral scutes and the acquisition of an intermediately sized plastron. The novel topology is significantly more consistent with the fossil record because it only implies minimal ghost lineages. Several interesting trends are apparent through time from the Early Cretaceous to the Holocene: (1) increase in overall body size; (2) increase in the relative size of the plastron; (3) reduction of the plastral and carapacial scutes; (4) reduction of the antrum postoticum; and (5) expansion of the fossa at the base of the processus articularis. These clear trends are certainly an artifact of the low diversity of the group and are therefore only mirrored by similar trends apparent among the lineage leading to Dermatemys mawii (Knauss et al. 2011).

\section{Paleobiogeography of Pan-Carettochelys}

Although records of carettochelyines are extremely rare in the Neogene (see Figure 7), they are geographically widespread, in contrast to the limited distribution of the extant Carettochelys 


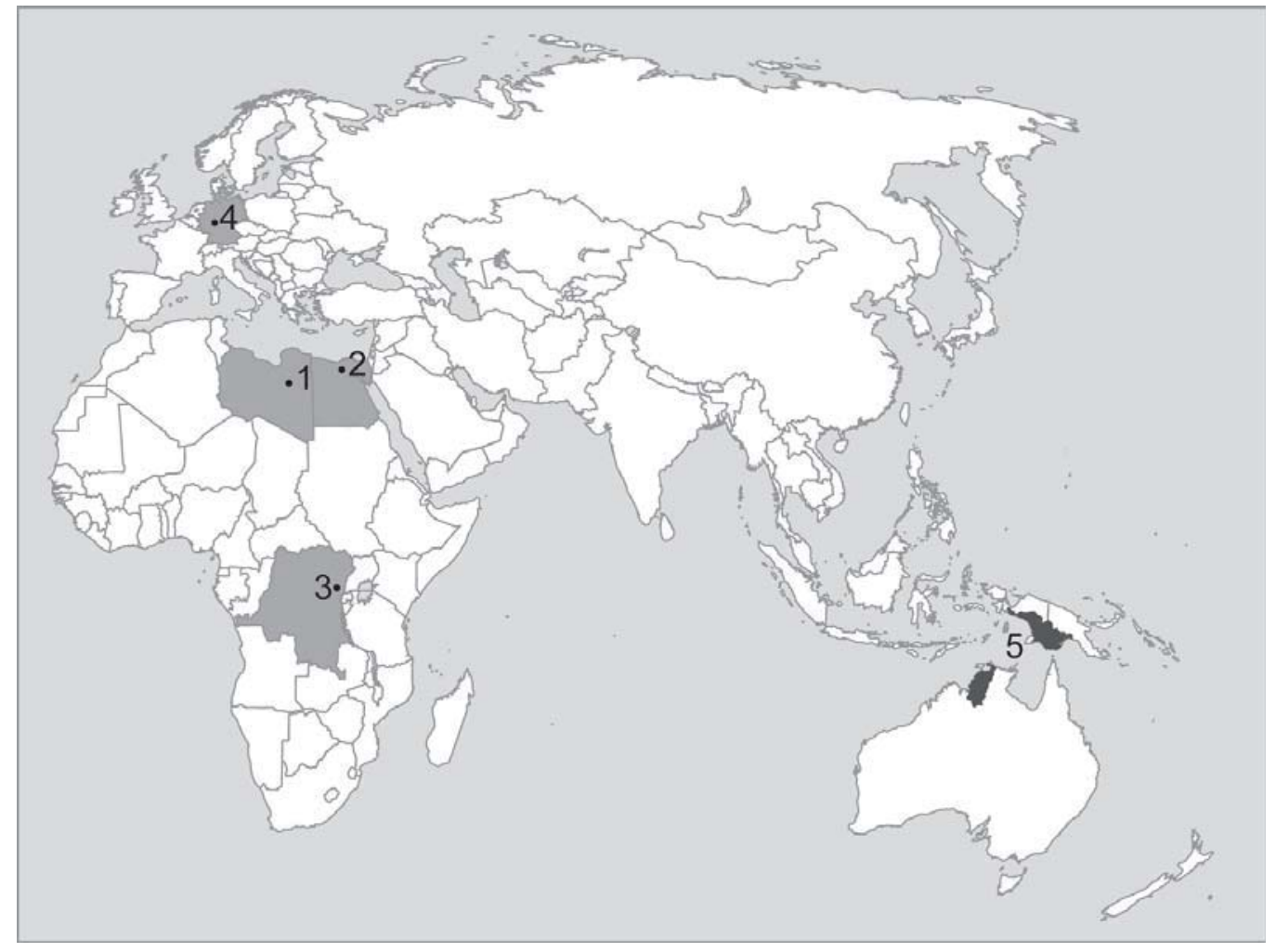

FIGURE 7. Distribution of Miocene Carettochelyinae (1-5) and extant Carettochelys insculpta (black): 1, Gebel Zelten, Libya; 2, Wadi Faregh, Egypt; 3, Sinda Basin, Democratic Republic of the Congo; 4, Hambach, Germany; 5, Kariava Creek, Papua New Guinea.

insculpta, which inhabits the island of New Guinea and the Northern Territory of Australia (McCord et al. 2003). The existing records of Neogene Carettochelyinae only consist of fragments. The best-preserved published record prior to this study is an articulated partial nuchal and first peripheral described by Dacqué (1912) as Cyclanorbis? from Wadi Faregh in northern Egypt (Lower Miocene). It was attributed to the genus Carettochelys by Roger et al. (1994) because of morphological similarities in the articulation of the girdle bones and surface sculpture but is herein referred to Allaeochelys. Stratigraphically, this fragment is attributed to the late Early Miocene (Dacqué 1912). Other Neogene fossils have been reported from the Miocene of Kariava Creek in Papua New Guinea (an external mold of a fragmentary nuchal; Glaessner 1942), from the Late Miocene to Early Pliocene of Sinda Basin in the Democratic Republic of the Congo (an isolated peripheral; Hirayama 1992) and from the
Middle Miocene of Hambach, Germany (an isolated peripheral; Joyce, Klein et al. 2004). Five anatomically undetermined fragments from the Miocene of Oman that were reported by Roger et al. (1994) to be similar to the material described in Dacqué (1912) were revised by Lapparent de Broin (2000) and attributed to the large testudinid taxon Geochelone. Meylan (2009) more recently mentioned the discovery of a partially preserved skull of a carettochelyine turtle from the Lower Miocene of Wadi Moghara, Egypt, but this material still awaits formal description. The articulated carapace of a presumed carettochelyid turtle from the Middle Miocene locality Retznei, Austria (Gemel and Rauscher 2000), is not a Carettochelyinae as it clearly displays carapacial scutes and more plausibly represents a marine turtle. Fragmentary remains attributed to "Carettochelyidae" were furthermore reported from the Miocene of Saudi Arabia (Thomas et al. 1982), but the lack of figures makes it impossible for us to verify this claim. 
The entire reproducible Neogene fossil record of Carettochelyinae is therefore restricted to less than a dozen fragments from six countries on four continents.

\section{Acknowledgments}

Wolfgang Gerber and Manuela Aiglstorfer (University of Tübingen) are thanked for exceptionally good photographs and for corrections of the manuscript. Oliver Rauhut (BSPG) is kindly thanked for loaning the specimen, and Wilma Wessels is acknowledged for contributing stratigraphic information regarding the site. Juliana Sterli and Márton Rabi are thanked for helpful discussions and insights that helped improve the quality of the manuscript.

Received 1 January 2014; revised and accepted 29 April 2014.

\section{Appendix 1: \\ List of Characters Used in the Phylogenetic Analysis}

Characters 1 to 59: see Joyce (2007).

Character 60 (Carapace A): 0, all carapacial scutes present; 1 , marginal scutes absent; 2 , all carapacial scutes absent.

Characters 61 to 88: see Joyce (2007).

Character 89 (Plastral Scutes A): 0, present; 1, reduced; 2, absent.

Characters 90 to 136: see Joyce (2007).

Character 137 (new): fossa behind articular process of quadrate (Walther 1922)—0, absent; 1, small; 2, large.

Character 138: depth of antrum postoticum (Walther 1922; Meylan 1988)—0, absent; 1, shallow; 2, deep.

Character 139: paired ventral processes of nuchal (Walther 1922; Meylan 1988)—0, absent; 1, present.

Character 140: vertebral I (Meylan 1988)—0, undivided; 1 , partly or completely divided along the midline.

Character 141: width of posterior plastral lobe (new character) -0 , wide; 1 , reduced; 2 , narrow.

Character 142: manual claws (Walther 1922; Meylan 1988) - 0 , five, 1 , four; 2 , three; 3 , two; 4 , one; 5 , zero.

Character 143: triangular entoplastron (new character)—0, absent; 1 , present.

Character 144: number of suprapygals (Meylan 1988)_ 0 , two or more; 1 , one.

Character 145: shape of pygal (new character)—anterior margin of pygal greatly thickened and with visceral groove.
Character 146: neural series (new character) - 0 , more or less continuous; 1 , neural series often disrupted by irregular midline contacts of costals.

Character 147: carapace with single midline keel (new character) -0 , absent; 1 , present.

\section{Literature Cited}

ANQUETIN, J. 2012. Reassessment of the phylogenetic interrelationships of basal turtles (Testudinata). Journal of Systematic Palaeontology 10:3-45.

BATSCH, A.J.G.C. 1788. Versuch einer Anleitung zur Kenntnis und Geschichte der Tiere und Mineralien. Jena, Germany: Akademische Buchhandlung. 528 pp.

BoulENGER, G.A. 1887. On a new family of pleurodiran turtles. Annals and Magazine of Natural History 19:170-172

BRoIN, F. DE. 1977. Contribution à l'étude des chéloniens. Chéloniens continentaux du Crétacé et du Tertiaire de France. Mémoires du Muséum National d'Histoire naturelle, Paris, Serie C 38:1-366.

- 1987. Lower vertebrates from the early-Middle Eocene Kuldana Formation of Kohat (Pakistan): Chelonia. Contribution from the Museum of Paleontology, The University of Michigan 27:169-180.

CHOw, M.M. AND C.-I. LIU. 1955. A new anosterine turtle from Maoming, Kwangtung. Acta Palaeontologica Sinica 3:275282. [in Chinese with English summary]

Clark, J. 1932. A new anosteirid from the Uinta Eocene. Annals of the Carnegie Museum of Natural History 21:161-170.

Cope, E.D. 1868. On the origin of genera. Proceedings of the Academy of Natural Sciences of Philadelphia 1868:242-300.

DACQUÉ, E. 1912. Die fossilen Schildkröten Aegyptens. Geologische und Paläontologische Abhandlungen 4:275-337.

DANILOV, I.G. AND J.F. PARHAM. 2008. A reassessment of some poorly known turtles from the Middle Jurassic of China, with comments on the antiquity of extant turtles. Journal of Vertebrate Paleontology 28:306-318.

Delson, E. 1979. Prohylobates (primates) from the early Miocene of Libya: a new species and its implications for cercopithecid origin. Geobios 12:725-733.

DESIO, A. 1935. Studi geologici sulla Sirenaica, sul deserto Libico, sulla Tripolitania e sulle Fezzan orientali. Missione scientifica della Reale Accademia d'Italia a Cufra 1:1-464.

Dollo, L. 1886. Première note sur les chéloniens du Bruxellien (Éocène moyen) de la Belgique. Bulletin du Musée Royal d'Histoire Naturelle Belgique 4:75-100.

ERNST, C.H. AND R.W. BARBOUR. 1989. Turtles of the World. Washington, DC: Smithsonian Institution Press. 290 pp.

FeJfar, O. AND I. HorÁČEK. 2006. The Early Miocene mammalian assemblages in Gebel Zelten, Libya. Lynx 37:95-105.

GAFFNEY, E.S. 1979. Comparative cranial morphology of recent and fossil turtles. Bulletin of the American Museum of Natural History 164:1-376.

Gemel, R. AND K. Rauscher 2000. Fossile Schildkröten aus Österreich (Reptilia: Testudines). Stapfia 149:63-89.

GiLmore, C.W. 1931. Fossil turtles of Mongolia. Bulletin of the American Museum of Natural History 59:213-257.

Ginsburg, L. AND E. Buffetaut. 1978. Euthecodonarambourgi n. sp., et l'évolution du genre Euthecodon, croco- 
dilien du Néogène d'Afrique. Géologie méditerranéenne 5:291-302.

GLAESSNER, M.F. 1942. The occurrence of the New Guinea turtle (Carettochelys) in the Miocene of Papua. Records of the Australian Museum 21:106-109.

GrifFIN, D.L. 2010. The late Neogene Sahabi rivers of the Sahara and the hamadas of the eastern Libya-Chad border area. Palaeogeography, Palaeoclimatology, Palaeoecology 309:176-185.

Hamilton, W.R. 1973. The Lower Miocene ruminants of Gebel Zelten, Libya. Bulletin of the British Museum (Natural History), Geology 21:75-150.

HARRASSOWITZ, H. 1922. Die Schildkrötengattung Anosteira von Messel bei Darmstadt und ihre stammesgeschichtliche Bedeutung. Abhandlungen der Hessischen Geologischen Landesanstalt 6:132-239.

HARRIS, J.M. 1973. Prodeinotherium from Gebel Zelten, Libya. Bulletin of the British Museum (Natural History), Geology 23:285-348.

HAVLIK, P. 2007. Reptilien (Crocodylia und Chelonia) aus dem Mittleren Miozän (Langhium) von Gebel Zelten (Libyen) und deren Bedeutung für die Paläoklimatologie [thesis]. München, Germany: Ludwig Maximilians Universität München. 108 pp.

HAY, O.P. 1906. On two interesting genera of Eocene turtles, Chisternon Leidy and Anosteira Leidy. Bulletin of the American Museum of Natural History 22:155-160.

-1908 . The fossil turtles of North America. Publications of the Carnegie Institute of Washington 75:1-568.

HIRAYAMA, R. 1992. Fossil turtles from the Neogene strata in the Sinda Basin, Eastern DR Congo. African Studies Monograph Supplements 17:49-65.

Hummel, K. 1929. Die fossilen Weichschildkröten (Trionychia). Geologische und Palaeontologische Abhandlungen 16:359-487.

Hutchison, J.H., P.A. Holroyd AND R.L. Ciochon. 2004. A preliminary report on Southeast Asia's oldest Cenozoic turtle fauna from the late Middle Eocene Pondaung Formation, Myanmar. Asiatic Herpetological Research 10:38-52.

JoYCE, W.G. 2007. A phylogeny of Mesozoic turtles. Bulletin of the Peabody Museum of Natural History 48(1):3-102.

-2014. A review of the fossil record of turtles of the clade PanCarettochelys. Bulletin of the Peabody Museum of Natural History 55(1):3-33.

Joyce, W.G., S.D. Chapman, R.T.J. Moody and C.A. WALKER. 2011. The skull of the solemydid turtle Helochelydra nopcsai from the Early Cretaceous (Barremian) of the Isle of Wight (UK) and a review of Solemydidae. Special Papers in Paleontology 86:75-97.

JoyCE, W.G., N. KLeIN AND T. MÖrs. 2004. Carettochelyine turtle from the Neogene of Europe. Copeia 2004:406411.

JoyCE, W.G., J.F. PARHAM AND J.A. GAUTHIER. 2004. Developing a protocol for the conversion of rank-based taxon names to phylogenetically defined clade names, as exemplified by turtles. Journal of Paleontology 78:989-1013.

Knauss G.E., W.G. Joyce, T.R. Lyson and D. Pearson. 2011. A new kinosternoid from the Late Cretaceous Hell Creek Formation of North Dakota and Montana and the origin of the Dermatemys mawii lineage. Paläontologische Zeitschrift $85: 125-142$.
LAPPARENT DE BRoIn, F. de. 2000. African chelonians from the Jurassic to the present: phases of development and preliminary catalogue of the fossil record. Palaeontologia Africana 36:43-82.

-2004. A new Shachemydinae (Chelonii, Cryptodira) from the Lower Cretaceous of Laos: preliminary data. Comptes Rendue Palevol 3:387-396.

LEIDY, J. 1871. Remarks on some extinct turtles from Wyoming Territory. Proceedings of the Academy of Natural Sciences of Philadelphia 1871:102-103.

LLINÁS AgrasAr, E. 2004. Crocodile remains from the Burdigalian (lower Miocene) of Gebel Zelten (Libya). Geodiversitas 26:309-321.

LYDEKKER, R. 1889. On remains of Eocene and Mesozoic Chelonia and a tooth of (?) Ornithopsis. Quarterly Journal of the Geological Society of London 45:227-246.

McCord, W.P., M. JosePH-OUNI AND J. CANN. 2003. Chelonian illustrations \#7. Short-neck, western swamp, and pignose turtles from Australia and New Guinea. Reptilia 27:64-68.

Meylan, P.A. 1987. The phylogenetic relationship of softshelled turtles (family Trionychidae). Bulletin of the American Museum of Natural History 186:1-103.

-1988. Peltochelys Dollo and the relationships among the genera of the Carettochelyidae (Testudines: Reptilia). Herpetologica 44:440-450.

-2009. A large new carettochelyine turtle (Testudines: Carettochelyidae) from the early Miocene of Egypt. In: Turtle Symposium; 2009 October 17-18; Abstracts and Program. Drumheller, Alberta, Canada: Royal Tyrrell Museum of Palaeontology. 116 pp.

MeYlan, P.A. AND E.S. GAFFNEY. 1989. The skeletal morphology of the Cretaceous Cryptodiran turtle, Adocus, and the relationships of the Trionychidae. American Museum Novitates 2941:1-60.

Nessov, L.A. 1976. On the systematics and phylogeny of two clawed turtles. Vestnik Leningradeskogo Universiteta 9:7-17. [in Russian]

-1977. Novyy rod dvukogotnykh cherapakh iz verkhnego mela Karakalpakii. Paleontologicheskii Zhurnal 10:103-114 [in Russian]

NoulET, J.-B. 1867. Nouveau genre de tortues fossiles proposé sous le nom d'Allaeochelys. Mémoires de l'Académie Impériale des Sciences, Inscriptions et Belles-Lettres de Toulouse 5:172-177.

PICKFORD, M. 2006. New suoid specimens from Gebel Zelten, Libya. Estudios Geológicos 62:499-514.

Rabi, M., C.-F. Zhou, O. Wings, S. Ge AND W.G. Joyce. 2013. A new xinjiangchelyid turtle from the Middle Jurassic of Xinjiang, China and the evolution of the basipterygoid process in Mesozoic turtles. BMC Evolutionary Biology 13:203. doi:10.1186/1471-2148-13-203

RAMSAY, E.P. 1887. On a new genus and species of freshwater tortoise from the Fly River, New Guinea. Proceedings of the Linnaean Society of New South Wales 1:158162.

Roger, J., M. Pickford, H. Thomas, F. De Lapparent de Broin, P. Tassy, W. Vanneer, C. Bourdillon-De-GrissaC AND S. AL-BuSALDI. 1994. Découverte de vertébrés fossiles dans le Miocène de la région du Huqf du Sultanat d'Oman. Annales de Paléontologì 80:253-273. 
SAVAGE, R.J.G. 1971. Review of the fossil mammals of Libya In: C. Gray, ed. Symposium on the Geology of Libya. Tripoli: University of Libya. pp. 215-225.

SAVAGE, R.J.G. AND W.R. HamiLton. 1973. Introduction to the Miocene mammal faunas of Gebel Zelten, Libya. Bulletin of the British Museum (Natural History), Geology 22:515-527.

SELLEY, R.C. 1966. The Miocene Rocks of Marada and the Jebe Zelten Area, Central Libya: A Study of Shoreline Sedimentation. Petroleum Exploration Society Guidebook, III. Tripoli: Petroleum Exploration Society of Libya. 30 pp.

Shuvalov, V.T. AND V.M. TCHIKVADZE. 1979. On stratigraphical and systematical position of some freshwater turtles from new Cretaceous localities in Mongolia. Trudy Sovmestnoy Sovetsko-Mongol'skoy Paleontologicheskoy Ekspeditsii 8:58-76. [in Russian]

STERLI, J., D. POL AND M. LAURIN. 2013. Incorporating phylogenetic uncertainty on phylogeny-based palaeontological dating and the timing of turtle diversification. Cladistics 29:233-246.

SwOFFORD, D.L. 2002. PAUP*. Phylogenetic Analysis Using Parsimony ( ${ }^{*}$ and Other Methods). Version 4. Sunderland, MA Sinauer Associates. Available from: http://paup.csit.fsu.edu/

TAWAdros, E. 2012. Geology of North Africa. London: Taylor and Francis. 931 pp.

Thomas, H., S. Sevket, M. Khan, B. Battail and G.C. LigABUE. 1982. The Lower Miocene fauna of Al-Sarrar (Eastern Province, Saudi Arabia). Atlal 5:109-136.
Tong H., J. Claude, V. Suteethorn, W. NAKSri and E. BufFETAUT. 2009. Turtle assemblages of the Khorat Group (Late Jurassic-Early Cretaceous) of NE Thailand and their palaeobiogeographical significance. Geological Society of London Special Publications 315:141-152.

Tong, H., V. Suteethorn, J. Claude, E. Buffetaut and P. JINTASAKUL. 2005. The turtle fauna from the Khok Kruat Formation (Early Cretaceous) of Thailand. In: Proceedings of the International Conference on Geology, Geotechnology and Mineral Resources of Indochina; 2005 Nov 28-30; Khon Kaen, Thailand. Khon Kaen, Thailand: Khon Kaen University. pp. 610-614.

TonG, H., J.-Y. ZHANG AND J.-J. LI. 2010. Anosteira maomingensis (Testudines: Carettochelyidae) from the Late Eocene of Maoming, Guangdong, southern China: new material and re-description. Neues Jahrbuch für Geologie Paläontologie, Abhandlungen 256:279-290.

Walther, W.G. 1922. Die Neu-Guinea-Schildkröte Carettochelys insculpta Ramsay. Nova Guinea 13:607-704.

Wessels, W., O. Fejfar, P. Peláez-Campomanes, A. Van der MeUlen AND H. DE BRUijn. 2003. Miocene small mammals from Jebel Zelten, Libya. Coloquios de Paleontología, vol. ext. 1:699-715.

YounG, C.-C. AND M. CHOw. 1962. Some reptilian fossils from the "red-beds" of Kwangtung and Chekiang. Vertebrata Palasiatica 1962:130-135. [in Chinese with English summary] ZANGERL, R. 1947. A new anosteirine turtle from Manchuria. Fieldiana Geology 10:13-21. 